\title{
Arqueología y género: nuevas perspectivas de investigación
}

Respuesta a las nuevas inquietudes en la investigación sobre las sociedades prehistóricas e históricas en nuestro país, el curso "Arqueología y Género", celebrado entre el 17 y 21 de marzo de 2003 en la Facultad de Filosofía y Letras de la Universidad de Granada, plantea importantes conclusiones especialmente vinculadas a las relaciones de género a partir del análisis de la documentación arqueológica, aspecto que, desde la década de los ochenta, ha despertado un gran interés entre la comunidad investigadora.

El origen de esta nueva línea de estudios tuvo lugar principalmente en los países escandinavos y anglosajones y fue protagonizado prioritariamente por mujeres que pusieron de manifiesto la relación entre su investigación y experiencias personales. La introducción de los estudios de género se reflejó en una triple vía en la que se prestaba atención al estudio de las relaciones de género en las sociedades pasadas, la historia de las mujeres arqueólogas y la situación actual de la mujer dentro de la profesión. En España, este movimiento tuvo, en un principio, escasa incidencia; sólo desde la última década de siglo XX se comenzó a prestar atención a estos aspectos, centrando el interés en temas como el uso indiscriminado del lenguaje que potencia la exclusión de la mujer y su completa anulación en la literatura arqueológica.

Afortunadamente, la inclusión del análisis de género en la arqueología es cada vez más frecuente. El desarrollo conceptual y metodológico desarrollado en otras disciplinas, tales como la geografia, la literatura o la historia contemporánea, ha sido asumido y enriquecido por arqueólogas españolas, principalmente de las universidades de Barcelona y Madrid, con una presencia cada vez más habitual en las universidades andaluzas. De esta forma la consideración de la mujer en el análisis de los grupos sociales prehistóricos e históricos ha comenzado a transformarse, y se abren nuevas perspectivas de análisis y debate. Sin embargo, este interés por la investigación de género que se refleja en la organización de algunas jornadas y publicaciones, no ha encontrado prácticamente ninguna cabida en los diseños curriculares de las enseñanzas universitarias. Únicamente algunos cursos especializados de tercer ciclo incluyen en sus programas este debate.

Por estas razones, desde la organización del curso se buscó ofrecer un amplio abanico de propuestas sobre las distintas formas de entender y practicar la arqueología de género, por parte de profesionales de distintas universidades con bagajes también muy distintos. El ámbito temporal resultó igualmente muy amplio, desde la Prehistoria a la actualidad, pasando por el mundo íbero, griego, romano y medieval. Los contenidos se estructuraron en torno a tres grandes bloques:

> Aspectos teóricos y metodológicos para el análisis de género en arqueología

$>$ Producción y tecnología

$>$ Presencia y representación de la mujer

\section{Margarita Sánchez Romero}

Dpto. Prehistoria y Arqueologia

Universidad de Granada

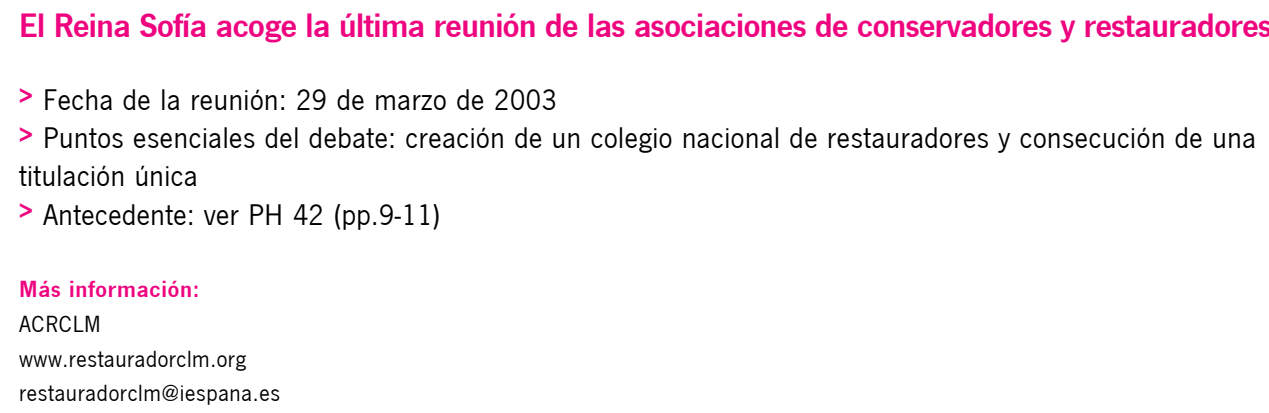

Los archivos españoles se abren a la red

A iniciativa del Ministerio de Educación, Cultura y Deporte, el proyecto Archivos Españoles en Red (AER) incorpora las nuevas tecnologías a los archivos con el objetivo de permitir el acceso inmediato y gratuito, a través de las siguientes direcciones web:

Archivos Españoles en Red (AER): http://aer.mcu.es/sgae/index_aer.jsp Censo-Guia de Archivos Españoles e Iberoamericanos: http://aer.mcu.es/sgae/index_censo_guia.jsp 